\title{
Applications, behaviour and construction of high performance steels in steel-concrete composite structures
}

\author{
B.Uy ${ }^{\mathbf{a} *}$

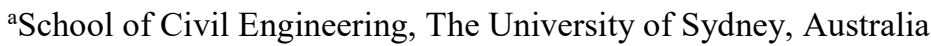 \\ *corresponding author, e-mail address: brian.uy@sydney.edu.au
}

\begin{abstract}
This paper addresses the applications, behaviour and construction of high performance steels in steel-concrete composite structures. For the purposes of this paper, high performance steels will include high strength, stainless and weathering steels. Akin to many innovations in the construction industry, high performance steels have generally been adopted for the use in iconic projects well before design procedures have been developed in standards. This paper will provide a summary of many of the applications particularly as they pertain to iconic projects in Australasia and internationally. Recent research in these areas will also be summarised and important design parameters as they deviate from traditional mild structural steel will be highlighted. Australasian advances in the standardisation of both bridges and buildings incorporating high performance steels will also be summarised, with particular reference to the Australasian Design Codes in Bridge Structures, ASNZS 5100 Part 6; and Building Structures ASNZS 2327 which have both been published in 2017. The paper will conclude with suggestions for further research and will identify areas of significant gaps in Australasian and international standards which will also guide future research in this area.
\end{abstract}

Keywords: Bridges; buildings; composite construction; high performance steels.

\section{Introduction}

Modern infrastructure demands higher performance, which in many cases is achieved through the improved strength and durability of the structural materials. Future bridges will demand longer and more durable spans and future buildings will also demand taller heights and reduced maintenance.

High strength steel has had some significant previous uses internationally. The benefits of high strength steel are principally in the reduced structural weight and area derived from their use. The juxtaposition of the use of high strength steel together with concrete can remedy many of the disbenefits that are often associated with high strength steel. The use of higher strength steels often means sections are more susceptible to local, global and coupled instabilities for a similar strength section to a mild structural steel member. Serviceability is often seen as being more controlling for a high strength steel flexural member when compared to a similar strength mild structural steel beam, however often the use of precambering can alleviate these issues. Furthermore, with increasing use of high strength steels in long span structures, prestressing is often employed to overcome the reductions in stiffness.

Stainless steel is being considered more prominently internationally in large scale iconic structures. Initially, the use of stainless steels was largely driven by architectural requirements in major projects, however the more recent innovations in stainless steel technology and the reduced costs has certainly seen stainless structural steels become cost competitive for structures in durability driven environments where whole of life cycle analysis can assist in the financial justification.

Weathering steels are a much more recent innovation in the high performance steel area, however have a very similar architectural drive to stainless steels and one finding particular favour in Australasia and internationally. 


\section{Applications}

Previous applications for many high performance steel structures internationally have been in steel-concrete composite forms. This is mainly since the cost differential of high performance steel over mild structural steel has required some sort of innovation to compensate for this. This section will highlight some of these salient examples for high strength, stainless and weathering steels.

\subsection{High strength steel}

High strength steel applications in Australia have been prevalent for three decades and ultimately have shaped the direction of future Australian Standards in Steel-Concrete Composite Construction, [1,2].

One of the first and most iconic of building projects in Australia to adopt the use of high strength quenched and tempered structural steel was the Grosvenor Place, completed in 1988. This building designed by the renowned architect, the late Harry Seidler, maximises the Sydney Harbour views over 44 floors and a total height of $180 \mathrm{~m}$ with an elliptical core, as illustrated in Fig. 1. This building incorporated the use of high strength quenched and tempered structural steel in the basement columns. High strength steel encased columns were utilised in the basement levels to group perimeter steel columns on the façade and to minimise the size and number of columns in the basement. This had the benefit of maximising the number of car spaces per level of car park and thereby reducing the significant excavation costs through high strength Sydney sandstone, [3].

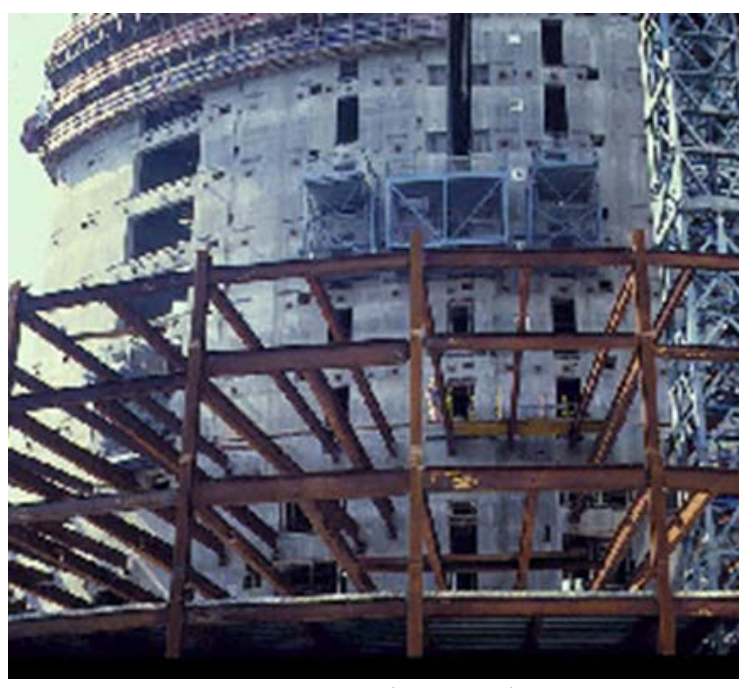

Fig. 1. Grosvenor Place, Sydney.
Star City (now known as the Star Sydney) upon completion in 1995 was the second largest building construction project in area to be completed in New South Wales since the Sydney Opera House, as illustrated in Figure 2. The project included two major theatres, two towers (both residential and hotel), as well as the main casino gaming floors and other entertainment venues. Located in an extremely confined part of Sydney, the project employed the design of high strength steel trusses to minimise craneage requirements on site. These trusses were made composite with topping slabs and posttensioned, further reducing the steel weight requirements. In addition the building also utilised the use of high strength steel encased composite columns to minimise the area of columns in the basement carpark levels, [4].

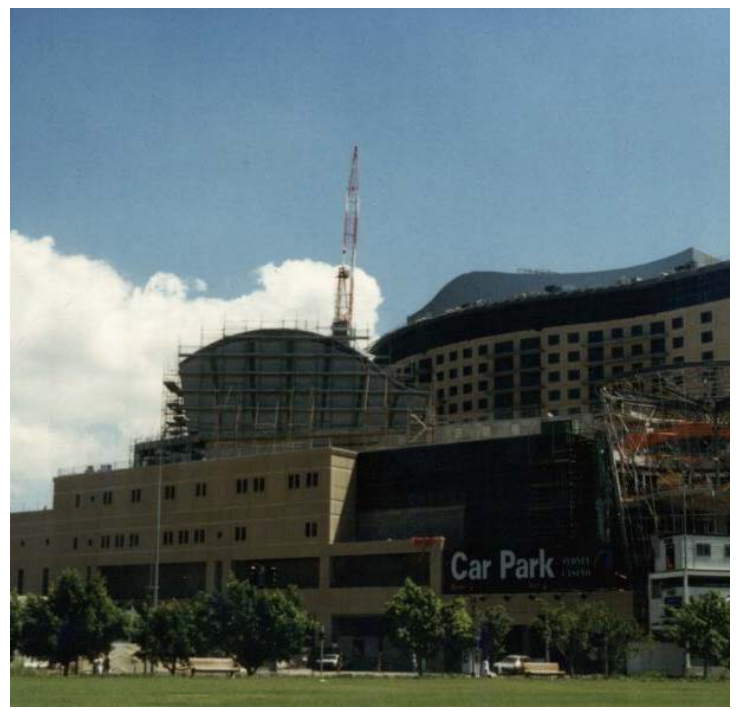

Fig. 2. Star City, Sydney.

Latitude is an iconic steel and composite commercial building over 45 floors and 222 metres in height and which was completed in 2004, [5] as illustrated in Fig. 3. The building adopted some novel forms of steel and composite construction. These included long span pre-cambered composite beams, twin tube columns filled with high strength concrete and some very large high strength steel transfer trusses, which were infilled with concrete. These transfer trusses were incorporated to allow the building to cantilever over the pedestrian level areas and take greater advantage of the air space toward the western edge of the building. The use of high strength steel box trusses allowed the minimisation of weight and thereby did not impact too greatly on onsite craneage requirements. The filling of these box trusses by concrete infilling on-site ensured that the truss 
members could be made composite with the high strength steel plates.

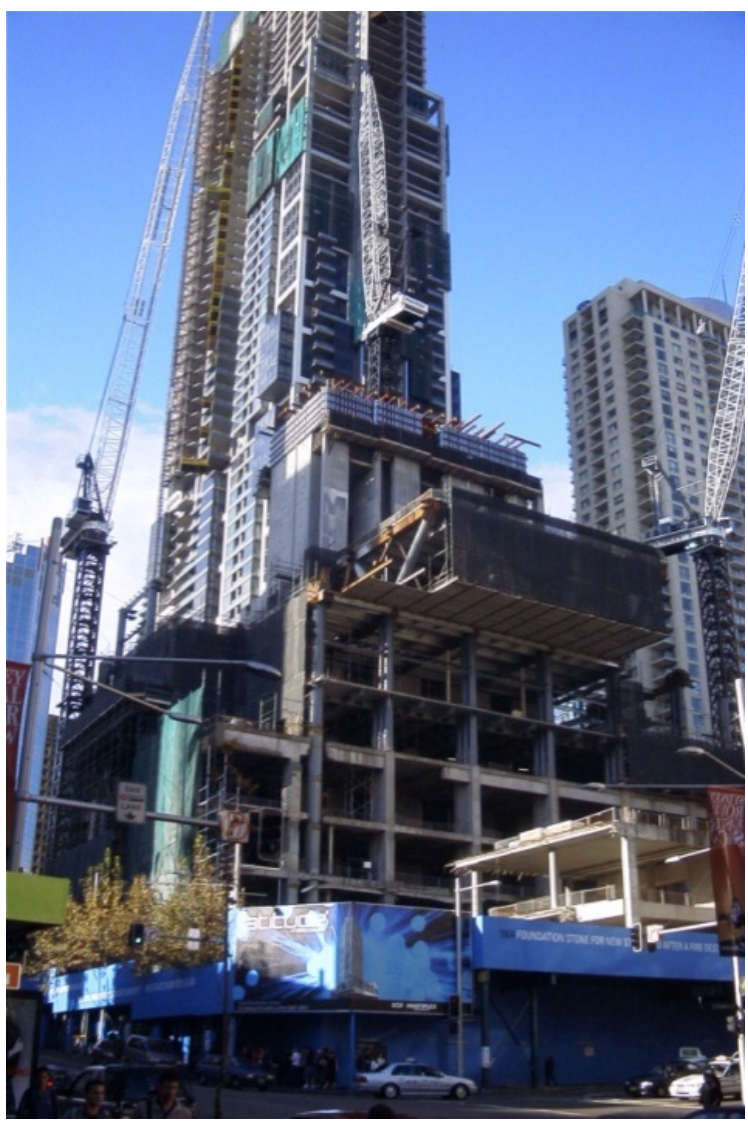

Fig. 3. Latitude, Sydney.

Internationally, on completion Taipei 101 in Taipei, Taiwan (Fig. 4) was the world's tallest building. Completed in 2004, it remained the tallest building until 2011 when the Burj Khalifa in Dubai was completed. This building is over 500 metres tall, with 101 stories in one of the most seismic regions of the world. From a construction innovation perspective this building achieved some significant firsts, including the use of high strength concrete up to $80 \mathrm{MPa}$ and the use of high strength steel up to $600 \mathrm{MPa}$. This was deployed in the large scale box columns used as mega-columns for both the gravity and lateral load resisting system of the building on the perimeter, [6].

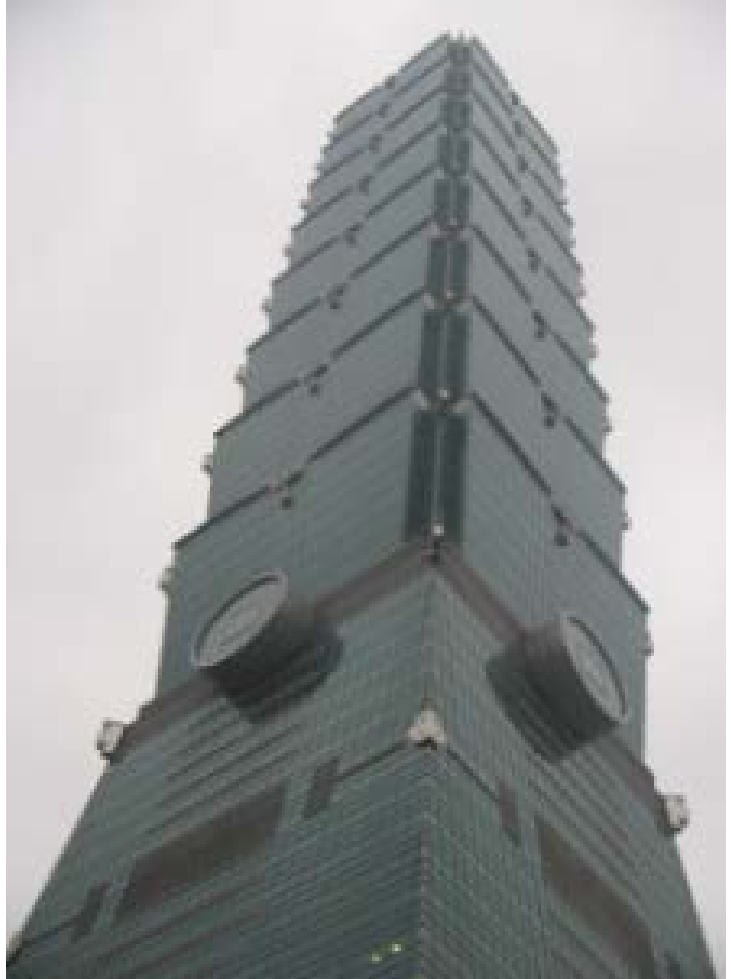

Fig. 4. Taipei 101, Taipei.

Completed in December 2016 and opened in early 2017 the Lotte Tower in Seoul, South Korea reaches skyward to over $550 \mathrm{~m}$ over 123 floors. It is currently the $5^{\text {th }}$ tallest building in the world. The building has been designed with the use of high strength of about $600 \mathrm{MPa}$ yield stress and $800 \mathrm{MPa}$ ultimate stress, [7]. The use of high strength steel in exterior mega-columns also utilised these for both the gravity and lateral load resisting systems.

The previous applications both Australian and internationally have illustrated that the use of high strength steel, coupled with concrete is assisting structural engineers to push the barriers in structural building heights. As urbanisation continues to increase around the world, there will be an increasing demand for the use of high strength steel, as this will helpful in providing the solutions to many of these future iconic projects. Materials advances, particularly in the mechanical and automotive industries for even higher strength steels up to $1000 \mathrm{MPa}$ ultimate stress, may further contribute and assist in solutions for tall buildings and longer span structures, [8]. 


\subsection{Stainless steel}

Stainless steel structural applications can provide significant economy when one considers the whole of life cycle costs of a structure. Stainless steel although significantly more expensive than carbon steel, has the benefits of significantly reduced maintenance. Furthermore, the mechanical and fire resistance of stainless steel is far superior to carbon steel. The benefits can be further enhanced by the juxtaposition of stainless steel with concrete to further improve the local, global and coupled instabilities of stainless steel-concrete composite structures.

Stainless steel structural applications have once again focussed on many previous iconic projects. The Gateway Arch in St Louis, Missouri completed in 1965 consisted of a 192 $\mathrm{m}$ arch and was designed by the renowned architect Eero Saarinen, [9]. The structural concept essentially is a doubled skinned composite structural tube with a stainless steel cladding, so essentially non-structural.

The flagpole of the Parliament House in Canberra was completed in 1988 in time for the Australian Bicentennial celebrations and is a very large structure, rising 81 metres and weighing some 250 tonnes, as illustrated in Fig. $5,[10]$.

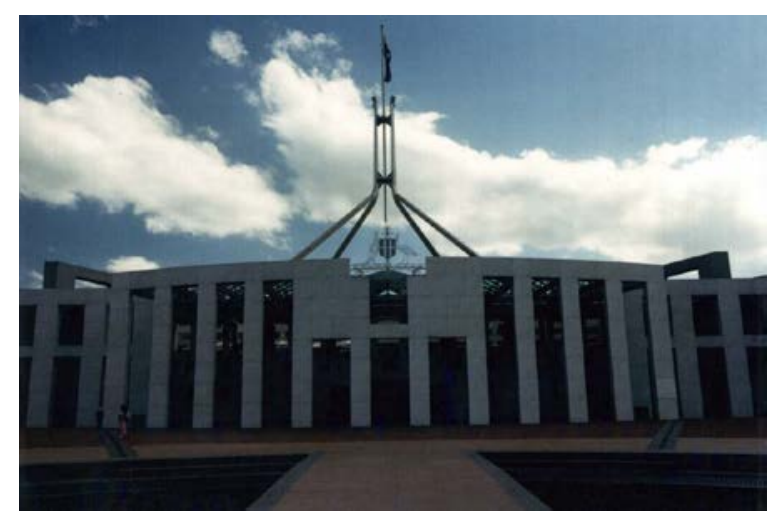

Fig. 5. Parliament House, Canberra.

Hearst Tower in New York, illustrated in Fig.6 used stainless steel boxed columns for the external diagrid lateral load resisting system, [11].

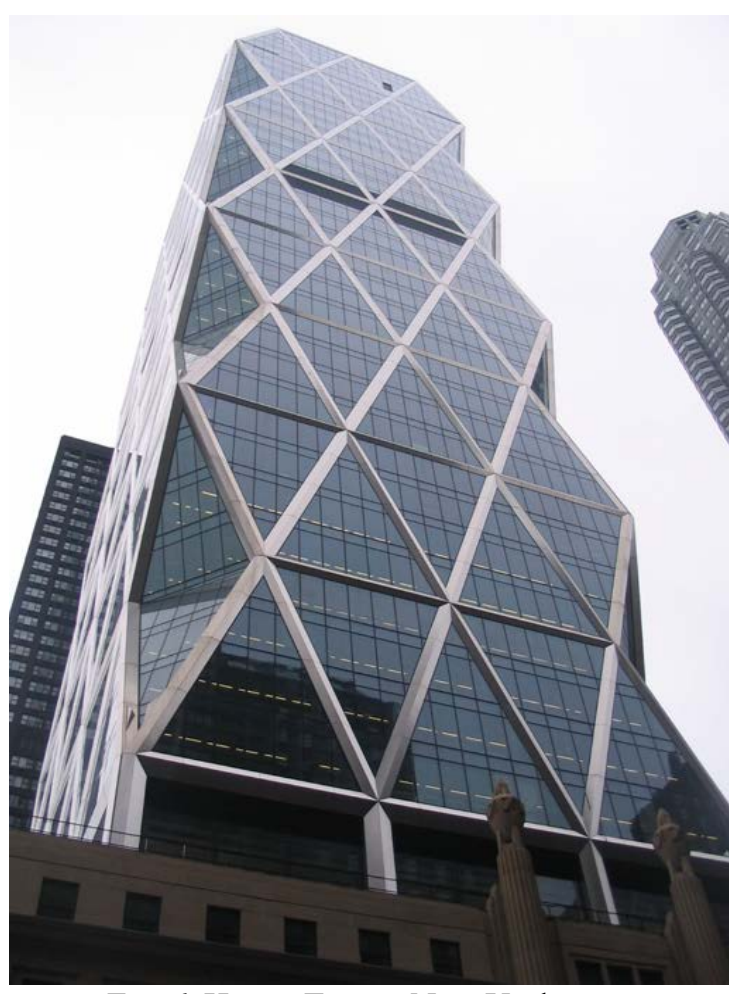

Fig. 6. Hearst Tower, New York.

The Stonecutters Bridge in Hong Kong with a 1018 metre span was the longest cable stayed bridge in the world upon completion, [12]. The bridge consists of two 290 metre tall masts with their upper third comprising of a stainless steel section filled with concrete.

\subsection{Weathering steels}

Weathering steels like stainless steels have the significant advantage of providing superior corrosion resistance and thereby can significantly reduce maintenance costs. Once again these need to considered in whole of life cycle costing of structures. Weathering steels are also very much associated with the architectural design of a structure and preferred in iconic structures. They however have quite a different paradigm and are diametrically the opposite of the shiny and new aestethic that stainless steel creates. Weathering steels convey an already corroded look and appear more rustic/used. They have however been used in some significant examples of Australian iconic structures, namely the Australia Pavilion at the World Expo in Shanghai in 2010, [13] and in the more recent use in a Deakin University footbridge in 2017, [14]. 


\section{Research}

The previous sections have highlighted that many of the previous iconic projects using high performance steels, have involved very large cross-sections, with most of these needing to be fabricated through conventional welding techniques. The large volumes of research related to steel or steel-concrete composite structures have often dealt with very thin steel sections, often fabricated from fairly light welding techniques. Also, many of the research projects on tubes have been carried out on cold formed tubes, which has many beneficial effects when compared with large fabricated polygonal sections which may be adversely affected by residual stresses and geometric imperfections which arise from heavily welded sections.

\subsection{High strength steel}

When using high strength steel, like all high performance steels, the benefits that can be derived from juxtaposing steel with concrete need to be optimised so that the initial capital cost outlay of a more costly fabricated structure can be offset by significant beneficial effects.

Uy [15 and 16] clearly outlined the benefits for short columns subjected to both axial and combined actions. With these two studies the improved slenderness limits over non-composite high strength steel sections was outlined.

Mursi and Uy [17] further highlighted the benefits of using high strength steel in slender composite columns. This study illustrated that one could optimise the column curve being used in slender column design and this was principally as a result of the reduced level of residual stress as a function of the member yield stress.

Mursi and Uy [18 and 19] further considered the effects of biaxial bending of high strength concrete filled steel box sections. This set of studies was particularly useful in highlighting the conservative nature of existing design provisions for biaxial bending and how the effects of material non-linearity can be used to further optimize the behaviour and design of these members.

More recently, Khan and Uy et al. [20 and 21] further extended the work in the area of high strength steel to incorporate the effects of high strength concrete of $100 \mathrm{MPa}$ compressive cylinder strength. Their studies considered both the effects of short and slender columns.

Khan et al. [22] also conducted one of the first studies on the effects of welding residual stresses on thick steel plates. Plate thicknesses of $16 \mathrm{~mm}$ were evaluated with multiple pass welding. The results of this study showed that previous studies on the effects of welding residual stresses on thinner plate steels may not be applicable to heavier welded sections and thus caution may be necessary in looking at this in the context of high strength steel used in practical projects.

Whilst significant research has been carried out on the behaviour of high strength steel in composite columns, there has been some research in the past that has focused on the behaviour of composite beams with high strength steel sections. Uy and Sloane [23] carried out a series of tests and developed a numerical model to evaluate the strength of a full and partially shear connected beam. Ban et al [24] carried out further numerical studies to assess the rotational behaviour of high strength steel-concrete composite beams.

\subsection{Stainless steels}

Stainless steel is typically significantly more costly than carbon steel, primarily because of the introduction of nickel and chromium which has the significant benefits of improving the corrosion resistance of the material. Optimisation for the use of stainless steel can be made by the beneficial effects that concrete has in delaying local and global instabilities. Stainless steel like other high strength steels also has the benefit of providing confinement to concrete for a marge larger range of strains than carbon steel, [25].

Significant research by Uy et al. [26] and Tao et al. [27] has shown the benefits that concrete infill provide both short and slender concrete filled steel columns.

Recent research, considering connections of stainless steel by Hasan et al. [28] also assists to understand how entire structures can be designed using stainless steel.

\subsection{Weathering steels}

At this stage, there does not appear to be any significant research that has been carried out in this area. 


\section{Codes of practice}

Over the last five years, two major projects have been ongoing in Australasia to develop revised design guidelines for bridges, ASNZS 5100, Part 6, [1] and buildings, ASNZS2327, [2]. These two design standards reflect the latest international developments in steel-concrete composite construction and also are unique as they incorporate design requirements for the highest strengths for concrete and steel internationally. These two standards allow for the design of steel-concrete composite structures with concrete compressive strengths up to 100 $\mathrm{MPa}$ and steel yield strengths up to $690 \mathrm{MPa}$.

\section{Conclusions and further research}

This paper has broadly outlined the area of the applications, behaviour and design of high performance steels in steel-concrete composite structures.

It is clear from the nature of the applications that high performance steels will have greater applicability in iconic projects. It is with these types of projects that standard sized cold formed and hot rolled sections are of limited applicability. These types of projects require large plate thicknesses and heavily welded sections are often required to form up the different types of cross-sections required. These types of structures have very particular types of methods of manufacture, which have not traditionally been researched in the area of steel or steel-concrete composite structures.

In assessing further research, it is clear that high strength steel beams have been considered, however would have fairly limited applicability. The behaviour of high strength steel-concrete composite infilled or encased columns have also been very well researched. Further research appears to be needed in the area of larger thickness plate sections, in particular to assess whether there are any through thickness or size effects associated with sections incorporating multi pass welding. Other further work could be carried out in the area of high strength composite connections as the larger loads that are being transferred would be more efficiently transferred through connections incorporating higher strength elements, such as bolts, plates and welds.
Very high strength steel up to $1000 \mathrm{MPa}$ is also being produced by plate manufacturers internationally. With the constant drive to taller buildings and larger span structures, higher strength steels can also assist to provide appropriate solutions for the future. The evaluation of plate slenderness limits, the assessment of short and slender column behaviour for columns composed of these types of materials will also be very valuable for the future.

Previous research in the area of stainless steel composite members has focused entirely on cold formed stainless steel members. There has been some preliminary work being carried out into the behaviour of fabricated stainless steel members. There is a need to carry out research into fabricated stainless steel sections made composite with concrete and covering the areas of beams, columns and connections. The assessment of plate slenderness limits and the consideration of residual stresses and geometric imperfections for large plate thicknesses is considered an important aspect for future applications and design of these structures.

Weathering steel has potential for many future applications, particularly in Australia, where the rustic aesthetic appears to blend in with natural landscapes. It appears that bridge infrastructure could have the greatest application. It is definitely considered necessary to carry out studies into the static and cyclic composite capacity of bridge girders incorporating steel girders with weathering steel.

\section{Acknowledgements}

The author would like to acknowledge the support of the Australian Research Council which is supporting the ongoing work in this paper through the awarding of the following two Discovery Project Grants, DP170100001, "Coupled service and ultimate behaviour of high strength composite columns", and DP180100418, "Behaviour \& design of large fabricated stainless steel composite structures". Ongoing experimental research is currently being funded through these two project grants. 


\section{References}

[1] Standards Australia AS/NZS 5100.6: Bridge design - Steel and composite construction, Australia; 2017.

[2] Standards Australia ASNZS2327-2017, Composite structures - composite steel-concrete construction in buildings; 2017.

[3] Grosvenor Place, URL: https://en.wikipedia.org/wiki/Grosvenor Place (Sydney), accessed 27/04/18.

[4] Star City, URL: https://en.wikipedia.org/wiki/The_Star,_Sydney , accessed 27/04/18.

[5] Latitude, URL:

https://en.wikipedia.org/wiki/Latitude (building 2, accessed 27/04/18

[6] Taipei 101, URL: https://en.wikipedia.org/wiki/Taipei_101, accessed 27/04/18.

[7] Lotte World Tower URL:

https://en.wikipedia.org/wiki/Lotte_World_Tow er, accessed 27/04/18.

[8] Ishii, T., Fujisawa, S. and Ohmori, A. Overview and application of steel materials for high-rise buildings, JFE Technical Report, No 14; 2009.

[9] Gateway Arch URL: https://en.wikipedia.org/wiki/Gateway_Arch , accessed 27/04/18.

[10] Parliament House URL: https://en.wikipedia.org/wiki/Parliament_House Canberra, accessed 27/04/18.

[11]Fortner B. Landmark reinvented, Civil Engineering Magazine, ASCE, 76(4): 42-49, 2006.

[12] Vejrum T, Bergman DW, Yeung N. Stonecutters Bridge, Hong Kong: Design and construction of the composite upper tower in stainless steel, Nordic Steel Construction Conference, Malmo, Sweden, 351-358; 2009

[13] Taylor A. Australia on Show, Steel Profile No $106 ; 2010$.

[14] Anon. Steel bridge goes above and beyond: Deakin University Burwood Link, Steel Australia, 26-27; December 2017.

[15] Uy B. Axial compressive strength of short steel and composite columns fabricated with high strength steel plate. Steel and Composite Structures 2001;1(2):171-185.

[16] Uy B. Strength of short concrete filled high strength steel box columns. Journal of Constructional Steel Research 2001;57(2):113134.
[17] Mursi M, Uy B. Strength of slender concrete filled high strength steel box columns. Journal of Constructional Steel Research 2004;60(12):1825-1848.

[18] Mursi M, Uy B. Behaviour and design of fabricated high strength steel columns subjected to biaxial bending: Part I : Experiments. Advanced Steel Construction: an international journal 2006;2(4):286-313.

[19]Mursi M, Uy B. Behaviour and design of fabricated high strength steel columns subjected to biaxial bending: Part II : Analysis and design codes. Advanced Steel Construction: an international journal 2006;2(4):314-354.

[20] Khan M, Uy B, Tao Z, Mashiri F. Behaviour and design of short high-strength steel welded box and concrete-filled tube (CFT) sections. Engineering Structures 2017;147:458472.

[21] Khan M, Uy B, Tao Z, Mashiri F. Concentrically loaded slender square hollow and composite columns incorporating high strength properties. Engineering Structures 2017;131:6889.

[22] Khan M, Paradowska A, Uy B, Mashiri F, Tao Z. Residual stresses in high strength steel welded box sections. Journal of Constructional Steel Research 2016;116:55-64.

[23] Uy B and Sloane RJ. Behaviour of composite tee beams constructed with high strength steel, Journal of Constructional Steel Research 1998;1(46):203-204.

[24]Ban H, Bradford M, Uy B, Liu X. Available rotation capacity of composite beams with highstrength materials under sagging moment. Journal of Constructional Steel Research 2016;118:156-168.

[25] Uy B. Stability and ductility of high performance steel sections with concrete infill. Journal of Constructional Steel Research 2008;64(7-8): 748-754.

[26] Uy B, Tao Z, Han L. Behaviour of short and slender concrete-filled stainless steel tubular columns. Journal of Constructional Steel Research 2011;67(3):360-378.

[27] Tao Z, Uy B, Liao F, Han L. Nonlinear analysis of concrete-filled square stainless steel stub columns under axial compression. Journal of Constructional Steel Research 2011; 67(11):1719-1732.

[28] Hasan M, Ashraf M, Uy B. Moment-rotation behaviour of top-seat angle bolted connections produced from austenitic stainless steel. Journal of Constructional Steel Research 2017;136:149161. 